\title{
A prática da adequação sociotécnica entre o campesinato: educação, ciência e tecnologia social ${ }^{1}$
}

Ricardo Toledo Neder

Universidade de Brasília

\section{Resumo}

No Brasil e na América Latina, o movimento pela tecnologia social tem sido ressignificado pelos estudos socioconstrutivistas da tecnologia (ESCT) nos quais ciência e tecnologia são processos gêmeos nas práticas sociotécnicas do cotidiano. Tal abordagem foi desenvolvida pelos autores da corrente da teoria da adequação sociotécnica (AST). Este artigo analisa três experiências cujos atores colocam em centralidade as práticas sociais e culturais como associadas às práticas técnicas, sem ruptura entre conteúdos sociais e formas técnicas nas relações econômicas. Resultado de acompanhamento sistemático de pesquisa nos últimos cinco anos, o campo das experiências paradigmáticas, aqui analisadas, exige uma abertura das políticas de educação científica e tecnológica da universidade, agências de pesquisas científicas e tecnológicas, e do sistema de fomento.

Palavras-chave: CTS. Tecnologia. Sociedade. Complexo agroalimentar. Adequação sociotécnica. CTS e Educação científica. Tecnologia social. Brasil.

1. 0 presente artigo está relacionado a projeto temático mais amplo intitulado Observatório do Movimento pela Tecnologia Social na América Latina (www.obmts.unb.br) relacionado a um conjunto de pesquisas para sistematização e análise de experiências paradigmáticas de adequação sociotécnica entre diversos movimentos em torno de políticas públicas de ciências \& tecnologia para arranjos autogestionários de economia solidária, grupos sociais urbanos e rurais no Brasil e América Latina, sempre considerando elementos sociocognitivos, aprendizagem e formação por experiências. O OBMTS tem apoio da CAPES - Escola de Altos Estudos (2009/2010 PROC.AUX.PE.EAE 1365/2009 e 2013/2014 proc. AUX-PE-EAE 042/2013), e Cnpq (projeto apoiado no edital ITCP mod. 1 proc. 420377-2013-1). Os dados aqui apresentados tem origem documental (secundária) e (alguns) dados qualitativos colhidos mediante entrevistas, conversas informais e por meio de metodologia de grupo focal com intelectuais orgânicos e lideranças populares das experiências (com exceção do Prove-Df). Agradecimento ao engenheiro agrônomo e prof. Dr. Adilson Jaime-Oliveira (Instituto Federal de Brasília - IFB) pela valiosa colaboração dos dados quantitativos e descritivos para o relatório final, alguns aqui incorporados - é da minha inteira responsabilidade sua utilização. 


\section{The sociotechnical adaptation praxis among peasantry - education, science and social technology}

In the first decade of the XXI century, a movement for social technology became part of the Social Constructivism of Technology (SCT) studies, by which Science and Technology are viewed as entwined in the sociotechnical processes of everyday life. In Brazil and Latin America, this SCT approach was developed by authors under the name of Sociotechnical Adaptation (STA) theory. This article analyzes three paradigmatic experiences whose social actors focus on social practices and technical improvements, without creating a breach between social and technical contents of social and economic relations. This kind of experience requires broadening scientific and technological policies, both in the University and in state agencies, such as the Ministry of Science, Technology \& Innovation.

Keywords: Rural Development. Education, Science, Technology and Society. Sociotechnical Adaptation. Social technology. Brazil.

\section{La práctica de la adecuación socio-técnica entre el campesinado: la educación, la ciencia y la tecnología social}

En Brasil y en América Latina, el movimiento por la tecnología social ha sido reinterpretada por los estudios tecnológicos socioconstructivistas (ESCT) en el que la ciencia y la tecnología son procesos paralelos en las prácticas sociotécnicas de la vida cotidiana. En Brasil y en América Latina este enfoque ha sido desarrollado por los autores de la teoría de la adecuación sociotécnica (AST). Este artículo analiza tres experimentos cuyos actores se centralizan en las prácticas sociales y culturales asociadas con el contenido técnico y práctico, sin ruptura entre las formas sociales y las técnicas en las relaciones económicas. Este tipo de experiencia requiere una apertura de la ciencia política y la educación tecnológica en el ámbito de la universidad, como las agencias de las políticas científicas y tecnológicas.

Palabras-clave: CTS. Tecnología y Sociedad. Complejo agroalimentario. Adecuación sociotécnica. Educación CTS y Ciencia. Tecnología social. Brasil. 


\section{Introdução}

Comparativamente aos grupos trabalhadores urbanos, tem sido constatado o reduzido nível de instrução formal dos grupos sociais rurais, em sua maioria, com ensino fundamental incompleto e com um quarto da população de analfabetos. Esta constatação não apresenta novidade; entretanto, quando anunciado pelos atores hegemônicos da política educacional brasileira, é utilizado para justificar a reprodução do modelo de escolarização tradicional, cujas soluções reforçam uma institucionalidade que gera mais exclusão educacional, pela impossibilidade de enfrentar o conjunto de obstáculos que pretende justamente superar.

Para entender melhor este debate, torna-se necessário fazer duas ressignificações. A primeira é compreender as experiências populares no complexo agroalimentar no interior dos referenciais teóricos dos estudos sociais da ciência e da tecnologia (ESCT). Com uma lente ainda mais específica, trata-se, em segundo lugar (no interior dos ESCTs), de adotar a abordagem teórica da adequação sociotécnica (AST), segundo a qual o ensino, pesquisa e extensão tecnocientíficas lidam com processos de trabalho coletivos, associativos e colaborativos entre diversos grupos sociais. Neste contexto a escolarização ou a vivência no aparelho educacional é uma dimensão, dentre outras também importantes.

Qual o locus das experiências formativas aqui mencionadas? Ele emerge do saber-fazer empírico e espontâneo que se mistura com o conhecimento técnico e gera um terceiro processo, de incorporação, que difere dos anteriores, o qual chamamos de adequação sociotécnica.

A criação e produção do conhecimento, desta forma, são interpretadas teoricamente como parte orgânica da própria sociedade, sem localizar estes locus no aparelho escolar, ou no grupo familiar, ou no coletivo de produção, isoladamente.

De forma similar, quando falamos de mudança tecnológica, evitamos separações do tipo avaliação, que opera com a noção de impactos da técnica sobre a sociedade (Benakouche, 2013, p.115-140). Para isto, os estudos ciência, tecnologia, sociedade têm sido adotados, há pelo menos duas décadas na América Latina, como estratégia teórico-metodológica que envolve teorias (críticas) sobre o funcionamento da sociedade, rechaçando a abordagem da tecnologia como partes ou conjuntos (científicos) ou de elementos discretos sob a forma de projetos, sistemas ou dispositivos tecnológicos que se apresentam como deterministas. (Dagnino, 2007; 2010a; 2010b; Feenberg, 2010; Santos, 2009; Thomas, 2009; 2011;) 


\section{0 debate sobre mudança técnica e agricultura}

De um ponto de vista favorável aos sujeitos dos movimentos sociais do campo, como podemos nos apropriar da mudança técnica (em gerall na agricultura? Os referenciais dos estudos CTS podem ajudar a responder esta questão, pois buscam algumas dimensões entrelaçadas com estudos mais antigos que realizaram a revisão das bases teóricas e políticas do conceito de tecnologia apropriada - conceito que foi superado, herança dos anos 1960. Icf. Abramovay, 2000; Almeida, 1989; Brandão, 2001; 2006, Carvalho, 1982; Dagnino, 2010a; Herrera, 2010; Graeml, 1996; Rodrigues; Barbieri, 2008). Nesse processo de superação do conceito de tecnologia(s) apropriada(s), e tomando por base a crítica dos Estudos Ciência, Tecnologia, Sociedade da literatura às teorias da inovação (neoclássica e a neo-shumpeteriana institucionalista, e seus matizes) podemos afirmar que as correntes interpretativas do final do Séc. XX ressignificaram a trajetória da modernização conservadora ou "revolução verde". Há duas direções, assim, desse movimento de reinterpretação:

a) enquanto crítica, ele tem mostrado que as vinculações entre universidade, Estado e empresas no Brasil orientam a política de ciência \& tecnologia hegemônica da comunidade científica lo que ocorre de forma cabal na agricultura empresariall, e

b) enquanto propositura de caminhos interpretativos e de base teórica para superar a concepção instrumental de tecnologia (seja pelas correntes tecnicistas, seja pelas correntes críticas humanistas), abrem-se novas possibilidades para um diálogo dos estudos CTS com as pesquisas que apontam os bloqueios para adoção de políticas científicas e tecnológicas direcionadas para o desenvolvimento e inclusão socioprodutiva (Baumgarten, 2008; Dagnino e Velho, 2011, Silva, 2013, (Dagnino, et. al., 2007)). Por fim, entram também neste segundo ponto referencial diálogos com as abordagens sobre ensino CTS de ciências, aplicadas a licenciaturas e bacharelatos do terceiro grau.

Na mídia impressa e eletrônica, este movimento tem assumido o referencial de senso comum como "tecnologia social", destacando os vínculos com agentes em movimentos mais amplos, reivindicatórios por mudanças estruturais nas estratégias de política social com ciência \& tecnologia. (Benini; Faria; Novaes; Dagnino, 2012; Dagnino, 2010b; Dagnino; Brandão; Novaes, 2010; Lassance Júnior et al, 2004; Neder, 2010; 2011; Santos; Auler, 2011; Thomas, 2009; 2011)

Outra vertente importante para considerar a questão da mudança técnica e políticas de educação ciência \& técnica, com e para os sujeitos dos movimentos sociais do campo, tem sido construída indiretamente pelas análises de economia política que descrevem os mecanismos de revalorização do complexo 
agroalimentar camponês e agrofamiliar, vinculado à necessidade de os sujeitos sociais do campo neutralizarem mecanismos de expropriação da sua renda. Ela tem sido historicamente realizada por grandes proprietários de terra, empresas capitalistas agroindustriais e empresas patronais rurais, todos dotados de acesso regular a recursos para impor perdas aos produtores mediante a adoção de inovações tecnológicas, poder de definir preços, contratos, mercados, domínio da terra e da mão de obra. Agem com suas cadeias de negócios, tecnologia e produção para transferir renda do setor rural para o urbano lamplas análises sobre estes mecanismos de expropriação encontram-se em Carter, 2010; Celgado, 2010; Fernandes, 1999; 2010; Medeiros, 2010). A tais processos se mescla a expropriação territorial de terras indígenas ancestrais no Brasil. (Little, 2002; Ribeiro, 1970, 1995)

Variados enfoques teóricos e abordagens temáticas foram desenvolvidas nos últimos 30 anos no Brasil e no exterior para explicar os processos pelos quais se dá esta expropriação. (Não há espaço aqui para reuni-los de forma compreensiva dada a dimensão, de quase um século, do debate no Brasil, produzido pela literatura especializada sobre as relações campo/cidade e mudança tecnológica na sociedade; para tanto consultar Abramovay, 2000; Almeida,1989; Almeida; Navarro, 1997; Alves, 2006; Bonnal, Cazella; Maluf, 2008; Fernandes, 1999; Furtado, 1966; 1967; 1968; 1972; 1974; Gorender,1978; Graziano-Silva,1987; Kageyama; Graziano-Silva, 1989; Guimarães, 1977; Hayami; Ruttan, 1985; lanni, 1992; Martine, 1991; Prado Junior, 1979; Romeiro, 1998; Veiga, 1991; Wanderley, 2000.

Numa abordagem típica dos estudos CTS, podemos identificar as condições subjacentes que envolvem educação, ciência e tecnologia na atualidade por meio de uma revisão de três experiências paradigmáticas nos últimos 15 anos, construídas por movimentos sociais e políticas públicas, envolvendo programas de mobilização comunitária no complexo agroalimentar camponês e familiar, a seguir apresentadas. Ao final serão analisados à luz de certas abordagens teóricas CTS.

\section{PDHC}

0 primeiro é o projeto Projeto Dom Helder Camara (PDHC) iniciado em 2002 e ainda em vigor, com aplicação, ao longo de 10 anos, de $R \$ 800$ milhões em subprogramas específicos e interrelacionados de segurança hídrica; saneamento básico; infraestrutura comunitária; segurança alimentar e geração de renda, além de produção não agrícola). Opera com produtores assentados da reforma 
agrária desde 2002 no Semiárido brasileiro. Iniciou com 4.226 famílias e, em 2009, saltou para 15.050 famílias em 337 comunidades na região, com uma média de incorporação de 2 mil famílias ano-a-ano. (PDHC, 2009)

0 PDHC tem sido avaliado pelo que representa de paradigma aplicado de experiência pública em cogestão, com comunidades envolvidas para 0 desenvolvimento rural sustentável em torno de territórios específicos. Um importante parceiro do PHDC e articulador regional é o Centro de Assessoria e Apoio aos trabalhadores e Instituições Não Governamentais Alternativas (Caatinga).

Essa entidade civil trabalha com o campesinato tradicional do sertão nordestino. Desenvolve experiências agroecológicas que operam sob dois eixos: educação para a transição agroecológica (parceria com agências internacionais e programas de governol e, em segundo, articulação de redes sociais locais para a definição de estratégias e propostas técnicas (em políticas públicas locais) capazes de colocar a extensão tecnológica, por intermédio de assessorias técnicas populares em contato com as populações do semiárido.

0 Caatinga, desde 1988, herdou a experiência com tecnologia apropriada (noção de que a técnica pode ser isolada do mercado ou da universidade, e convertida em aplicação útil pelos próprios agentes sociais) do Centro de Tecnologias Alternativas de Ouricuri (CTA-0) ligado ao Projeto Tecnologias Alternativas da FASE (Federação dos Órgãos para Assistência Social e Educacional) e Rede PTA (Programa Tecnologias Apropriadas) (Caatinga, 2012). A ação do PDHC se estende a todo o Semiárido brasileiro devido ao seu papel de eixo das articulações em encontros e fóruns. (Caatinga, 2012; Phdc, 2009)

Suas experiências paradigmáticas de gestão do complexo agroalimentar familiar são discriminadas a seguir por grandes áreas:

a) Assessoria Técnica e Construção de Conhecimento Agroecológico - Ação direcionada ao fortalecimento da agricultura familiar no Sertão Pernambucano. A experiência denominada (sub) Projeto Campo Ativo é uma iniciativa do Caatinga, uma das 13 organizações não governamentais com atuação no Nordeste brasileiro que formam a Rede ATER Nordeste. Trata-se de uma articulação específica do semiárido brasileiro voltada para a prática de assistência técnica para o complexo agroalimentar regional, que busca precisamente desenvolver um sistema alternativo de assessoria técnica e extensão rural baseado na agroecologia. Tem forte atuação entre jovens por meio do agentes promotores de agroecologia (APAs). (Caatinga, 2012)

b) Novas Rendas Sertanejas - Fomento à geração de renda e oportunidade de trabalho, voltado para a melhoria da comercialização de produtos agroecológicos 
da agricultura familiar no semiárido. Seu objetivo principal é tornar mais conhecidos pela população consumidora os produtosagroecológicos das famílias do Sertão do Araripe (PE), melhorar e ampliar os canais de comercialização e aumentar sua produção. (Caatinga, 2012; Phdc, 2009; Phdc; 2012)

\section{PROVE-DF}

A segunda experiência se refere ao Programa de Verticalização da Pequena Produção Familiar (Prove/DF, 1995-98). Avaliações multidimensionais da experiência indicam relativo avanço do programa, pois, após três anos de funcionamento (até 1998), operavam 73 agroindústrias familiares, com cerca de 123 famílias, que criaram 112 produtos no território do Distrito Federal. (Brandão, 2001, 2006)

As avaliações indicam que as iniciativas, desde o seu início, encontraram grandes dificuldades devido às críticas oriundas da própria comunidade científica, que identificou no programa um concorrente aos recursos disponíveis para projetos convencionais de ciência e tecnologia. (Brandão, 2001, 2006)

As famílias que se dedicaram à produção tecnicamente orientada de alimentos adotaram procedimentos higiênicos e sanitários na agroindústria. Sessenta e quarto por cento ficaram satisfeitos com o espaço físico das minifabriquetas, 54\% apoiaram o uso dos equipamentos existentes, e $90 \%$ declararam ter participado de pelo menos um curso promovido pelo programa. Noventa e oito por cento seguiam as recomendações técnicas repassadas pela assistência técnica. Noventa e três por cento foram motivados pela confiança nas equipes técnicas do programa e valorizaram sua disponibilidade, envolvimento com os problemas dos produtores e sua capacidade assertiva. (Brandão, 2001,2006)

Os produtores entenderam o programa como um caminho para saírem da clandestinidade, 93,2\% declararam ser favoráveis à legalização das agroindústrias, optando pelo enquadramento formal de microempresas. Setenta e oito por cento faziam "algum" controle e/ou contabilidade dos gastos e dos lucros do empreendimento - 40,7\% por conta própria, 22\% com ajuda da Emater/DF e 15,3\% se valendo de outros recursos. Já no primeiro ano de existência, a agroindústria tornou-se fonte de renda complementar para $45,6 \%$ dos produtores, única para $31,6 \%$ e principal para $22,8 \%$. (Brandão, 2001,2006)

A segunda dimensão crítica se expressou por meio da resistência dos quadros regulares de extensão e assistência técnica quanto a se engajar no programa. Não havia quadros técnicos que pudessem organizar os pequenos produtores para redes de comercialização. A organização social dos produtores não funcionou, e, 
por falta de capacidade reivindicativa coletiva, tão logo findou o período da gestão que promoveu o programa, praticamente deixou de operar.

\section{ASA}

A terceira experiência significativa é a da Articulação no Semiárido Brasileiro, ou ASA, que se tornou nacionalmente conhecida pelo papel de rede que reúne centenas de outras redes sociais comunitárias, além de uma entidade mobilizadora de apoios técnicos para as comunidades chegarem à construção, em regime de autogestão, de 368 mil cisternas (Programa Um Milhão de Cisternas ou P1MC) com capacidade para armazenar 16 bilhões de litros de água da chuva. (Asa Brasil, 2012b)

O Semiárido brasileiro é uma região cujos municípios estão organizados em pequenos e médios centros urbanos, "a maioria em péssima situação financeira e com infraestrutura deficiente; (...) as políticas macroeconômicas e os investimentos públicos e privados têm tido, muitas vezes, efeitos perversos: terminam por gerar novas pressões, que contribuem aos processos de desertificação e reforçam as desigualdades econômicas e sociais". (Lopes; 2007)

A ASA, diante disso, é mais do que uma simples entidade civil, pois assume o papel de agência regional informal, rede cooperativa e núcleo de pesquisa e extensão, ao realizar uma política de educação científica e tecnológica implícita (não reconhecida pelo circuito do sistema de C\&T e educacional governamental).

Pesquisas de avaliação realizadas sobre esta dimensão ressaltam que 0 conhecimento científico e tecnológico tem se voltado principalmente ao estudo de propostas inadequadas ao semiárido brasileiro, insustentáveis do ponto de vista social e ambiental. (Albuquerque, 2011)

Busca o acesso descentralizado de água potável para um milhão de famílias (5 milhões de pessoas) por meio de processos de formação, educação e mobilização de pessoas e instituições para criar oportunidades na articulação das experiências locais e territoriais de convivência sustentável com o Semiárido.

Os esforços se juntam com base em experiências sociotécnicas simples, como a construção de cisternas de placa para armazenagem de águas de chuva. A cisterna de placas possui formato cilíndrico, coberta e semienterrada, captando a água da chuva conduzida por calhas instaladas nos telhados das casas. 0 reservatório tem capacidade para armazenar até 16 mil litros de água, suficientes para uma família de 5 pessoas beber e cozinhar, por um período de 6 a 8 meses - época da estiagem na região (Asa Brasil 2012a). Os dados atuais da ASA indicam a cogestão (comunidades e Governo Federal) na construção de 376.545 cisternas. 
O Caatinga, antes analisada, é uma Unidade Gestora Microrregional e Unidade Gestora Territorial da ASA. Já mobilizou comunidades para construir oito mil cisternas (envolvendo 40 mil pessoas). A exemplo do Caatinga existem outras 749 entidades civis com função similar.

0 P1MC, desde julho de 2003, tem como objetivo atingir As experiências marcantes da ASA podem ser agrupadas em quatro eixos estruturantes, nos quais a experiência, a aprendizagem, os artefatos e as soluções técnicas formam um continuum, e são indissociáveis no dia a dia dos grupos comunitários:

1. Manejo sustentável da água e recursos hídricos - Programa Uma Terra e Duas Águas $(\mathrm{P} 1+2)$. 0 objetivo do $\mathrm{P} 1+2$ é ir além da captação da água de chuva para consumo humano, é avançar para a utilização sustentável da terra e manejo adequado dos recursos hídricos para produção de alimentos lanimal e vegetall, promovendo a segurança alimentar e a geração de renda junto com 144 tecnologias de captação de água da chuva, entre as quais cisternas de calçadão e barragens subterrâneas para a produção de alimentos que beneficiarão 818 famílias.

2. Plataforma de políticas públicas para a região - A partir dos projetos experimentais se destacam dois aprendizados da ASA. Avaliar, monitorar e sistematizar experiências propositivas a partir de projetos pequenos, em escala piloto, e daí chegar às propostas territoriais e regionais. Tal aprendizado é o resultado das ações do P1+2. (Lopes, 2007; Albuquerque, 2010; Asa Brasil, 2006; 2009)

3. Banco de sementes - A Casa de Sementes Regional armazena sementes crioulas para garantir a preservação de todo o patrimônio genético, gerando também autonomia para os agricultores frente ao mercado de sementes híbridas. Esta experiência tem como fundamento a experiência da ASA de fortalecimento da agricultura familiar, central na estratégia de convivência com o semiárido, baseado em módulos fundiários compatíveis com as condições ambientais. Processos de desertificação são encarados como estritamente correlacionados com desigualdades econômicas e sociais. (idem. Ibidem)

4. Políticas de convivência com o semiárido - Estas políticas têm por base as experiências sociotécnicas (barragem subterrânea, casa da semente crioula, rotação de cultura, adubagem verde, cultivo em curva de nível, organização de associações e criação de pequenos animais; bacias de contenção de água da chuva; horticulturas e Produção Agroecológica Integrada e Sustentável (Pais). (ib.id) 


\section{0 debate sobre mudança técnica, agricultura e educação formal}

A literatura dos anos 2000 tem afirmado que as formas de resistência contra a (já mencionada) expropriação dos pequenos proprietários e grupos camponeses pelo capital na agricultura tem assumido duas características ao longo das últimas décadas: (i) houve relativa perda de importância dos movimentos de assalariados rurais, e (ii) houve ascensão da luta para o reconhecimento da identidade, interesses e demandas do campesinato e pequenos agricultores no País. (Delgado, 2010; Fernandes, 2010; Medeiros, 2010)

Numericamente o complexo agroalimentar familiar e camponês corresponde a $84 \%$ dos 5,17 milhões de estabelecimentos agropecuários (4,3 milhões) responsáveis por $77 \%$ da ocupação no meio rural. Respondia por $37 \%$ da produção agrícola brasileira e oferta de quase $70 \%$ em média de alimentos na cesta básica. (Schneider; Mattei e Cazella, 2004; Brasil-lbge, 2009a, Alves, 2006)

Uma classificação administrativa aponta-os como produtores com até 4 módulos fiscais - módulo fiscal corresponde à área mínima necessária para explorações economicamente viáveis. É variável para cada município (Brasil, 1979; Brasil, 1993). Cerca de $80 \%$ destes contingentes são atendidos com recursos governamentais.

Esse quadro é insuficiente porque o recurso para agricultura familiar abrange apenas $32 \%$ do montante total da ajuda governamental para agricultura, e os segmentos patronal e empresarial têm se apropriado da maior parte. Em contrapartida, a agricultura empresarial e patronal lestabelecimentos com área superior a mil hal compõe $1 \%$ dos estabelecimentos com financiamentos no País. Eles captaram $44 \%$ do total de recursos governamentais. (Brasil - IBGE, 2009b)

Dados do censo indicam que os estados nordestinos apresentam menor nível de escolarização e maior conteúdo artesanal na produção agropecuária, com menos uso de dispositivos e sistemas técnicos. As diferenças nos estabelecimentos observadas em 2006 assemelham-se às diferenças observadas por Freitas, Bacha e Fossati (2007) entre os estados da Federação para o período 1970-2000. Por estes dados, o desenvolvimento da agropecuária depende diretamente das habilidades e conhecimento médio dos trabalhadores e empresários.

0 censo 2006 confirma o reduzido nível de escolarização formal dos grupos sociais rurais. A maioria possui o ensino fundamental incompleto. Quinze por cento só sabem ler e escrever enquanto $24,5 \%$ não sabem ler nem escrever. A profissionalização é reduzida no campo: somente $3 \%$ possuem curso superior e $1,35 \%$ possui curso de técnico agrícola.

Pesquisas que estimaram a convergência do PIB agropecuário, utilizando 
uma abordagem estatística especial, indicaram a tendência no longo prazo lapós 2005) de que $67 \%$ dos estados seriam mantidos em uma classe inferior à média brasileira do PIB agropecuário per capita. Apenas $11 \%$ dos estados se destacariam acima da média (Pessoa et al., 2009). Este tipo de constatação refere-se a uma compreensão do crescimento da produção e sua correlação com o crescimentoeconômico: mantidas as atuais tendências, ambos não seriam capazes de reduzir as diferenças regionais sem políticas de educação e pesquisa científica.

Esta correlação é enviesada, como sabemos, porque toma como referência a noção de crescimento pela dimensão física da produção e demais transações econômicas. Mas importa contestar outro lado desta visão: ela contem, implícitamente, o pressuposto de que, quanto mais e mais bem escolarizados e capacitados os/as produtore/as familiares e campesinato, melhores são os resultados que podem obter no acesso aos recursos das políticas públicas, por saber lidar com os trâmites administrativos, superar burocracias e encontrar força política para acessar, por exemplo, melhores condições de oferta regular de crédito rural.

Aquino et al. (2011), neste ultimo sentido, afirmam esta correlação: as políticas de ampliação do crédito para o Programa Nacional de Fortalecimento da Agricultura Familiar (Pronaf) não atingem a maioria dos grupos sociais camponeses e de agricultura familiar no Brasil, deixando de fora quase $60 \%$ de seus contingentes, porque os atores sociais seriam insuficientemente preparados ou qualificados para entrar na cadeia de gestão de serviços administrativos, financeiros, técnicoburocráticos dos créditos.

Para supostamente comprovar isto, descobriu-se, já há algum tempo, que o mais expressivo em termos de população é o grupo "B" destes grupos do PRONAF. Estimativas realizadas por Sabbato (2000, apud Aquino et al., 2011) dão conta que este segmento englobava nada menos que $53,4 \%$ do total de estabelecimentos camponeses brasileiros identificados pelo Censo Agropecuário 1995/1996. Ou seja, de cada 100 estabelecimentos recenseados na época mais da metade tinha rendimentos anuais até $R \$ 1.500,00$, concentrando-se em seu interior o grosso da pobreza rural do País.

Grande parte destes investimentos, contudo, está concentrada nas formas de transferência do crédito para plantio. Nota-se que esta modalidade de investimento público nada tem a ver com o que é reivindicado como política de capacitação, qualificação, saberes ou escolarização que levem em conta a visão sobre crescimento econômico e sua correlação com educação está, como pode ser facilmente constatável, formulada para tornar o campesinato e o agricultor familiar um agente econômico irracional na melhor perspectiva 
neoliberal, excluído do mercado de crédito por sua própria incapacidade ou insuficiências relacionadas No lugar destas e de outras sandices em torno da missão do crédito, ou do microcrédito como operadores mágicos da inclusão socioeconômica, devemos - em vez de perguntar se os atores sociais têm ou não condições educacionais, técnicas e administrativas de atingir o crédito ofertado - indagar por que os mecanismos oficiais, de fato, não são formulados para promover a incorporação destes atores sociais por meio de uma outra dimensão na qual os saberes e técnicas locais, em conjunto com bases científicas, possam ampliar o leque de acesso das populações hoje atendidas pelo Pronaf (Programa Nacional de Agricultura Familiar)? Estes repasses podem crescer para aumentar o conteúdo proativo de fomento às ações sociotécnicas dos saberes próprios destes contingentes hoje excluídos? Estamos, portanto, diante de dois problemas: não basta o fomento à inclusão dos saberes camponeses e tradicionais; adicionalmente torna-se fundamental uma alteração da postura das políticas públicas de um estágio ofertante para outro de busca proativa, para adaptar as condições legais e administrativas, técnico-burocráticas dos editais de chamada aos mecanismos de entrada (elegibilidade e seletividadel e ao perfil de atores sociais. Se a fatia majoritária deste crédito se mantiver destinada à comercialização e ao seguro agrícola, nãohaverá muito avanço porque apenas uma fatia menor (10-15\% dos recursos federais do crédito) tem sido destinada às políticas de melhorias na extensão e gestão da capacitação. E como estamos em termos de cobertura? O Censo Agropecuário (Censo de 2006) aponta que $78 \%$ não recebem assistência técnica e extensão; $13 \%$ recebem ocasionalmente, e apenas 9\% recebem regulamente (Brasil-lbge, 2009 b)! Se formos esperar a inclusão de $91 \%$ da população economicamente ativa nos quadros desta assistência, precisaremos de um horizonte provavelmente de um século! Diante deste quadro inviável, qual a solução? Uma primeira constatação geral é incorporar o caráter das experiências formativas, que são fundamentais para ampliar a noção de trabalho qualificado e inclusão socioprodutiva: de qualquer ótica que queiramos olhar, as experiências do saber-fazer dos contingentes sociais do campo incorporam a dimensão chave de trabalho imaterial dos atores. Para incorporar conhecimento ou saberes imateriais do ponto de vista que interessa à mudança sociotécnica dos próprios grupos camponeses e agrofamiliar, é necessário destacar a dimensão heurística das experiências. A capacidade heurística do saberfazer (enquanto característica humana geral) assume um lado positivo como a arte de descobrir ou inventar a resolução de problemas por meio de experiências (próprias ou observadas). Enquanto método, a experiência formativa é heurística na medida em que capta o vivido processual lsob a forma de resolução de um problemal e o reproduz como hábito. 0 processo se tornará elemento cognitivo 
explicativo dos próprios atos, oferecendo soluções viáveis (não necessariamente a melhor). 0 trabalho imaterial dos produtores subjaz invisível, em geral, aos esforços dos programas e subprojetos oficiais. As experiências heurísticas estão presentes nos saberes tácitos, na produção e processamento de alimentos, conservação da biodiversidade e agrodiversidade, conhecimento do clima e solo, domínio de técnicas agrícolas básicas, e, sobretudo, domínio coletivo das sementes (germoplasmas das plantas). Tudo se passa, no circuito oficial, como se estas funções sociais altamente relevantes para uma concepção de conservação e desenvolvimento endógeno e sustentável não existissem nas políticas oficiais ou de mercado que se relacionam com a agricultura camponesa e agrofamiliar. Apresentamos, a seguir, proposta que leva em conta a dimensão dos saberes e fazeres. Eles podem dialogar com a métrica de identificação e classificação do conhecimento com a base científica e tecnológica hegemônica? Poderão vir a se tornar base de elegibilidade e critério de financiamento mais refinado nos editais oficiais de todo tipo (Pronaf, Capes, Cnpq, Incra, Mda, Secis/Mcti...)? Estas e outras perguntas são respondidas na seção final.

\section{Sete marcadores de adequação sociotécnica como metodologia heurística}

A partir da base teórica AST dos estudos CTS, podemos situar sete marcadores que ressignificam as experiências formativas dos sujeitos sociais envolvidos. Veremos sob a forma de perguntas e respostas como se configura cada um dos marcadores para as experiências formativas do sujeitos. Assim, passamos a uma releitura das três experiências antes descritas (Phdc, Prove-DF e Asa).

a. Como pode o mapeamento participativo da sua condição técnica (existencial) ser um processo vivido pelos próprios agentes sociais? Este marcador de vivência dos sujeitos do campo é fundamental como despertar. Tanto no projeto Dom Helder Câmara, quanto na experiência da cisterna de placas da ASA e também nas minifabriquetas do PROVE, há grupos relevantes de produtores e técnicos como ator central. 0 grupo relevante é formado por produtores agroalimentares envolvidos nas ações de reconfiguração de papéis e projetos destinados a promover o uso da tecnologia, sob as características culturais e técnicas locais /cisterna de placa, agroecologia, plantios compartilhados, novas formas de organização do processo de trabalho, acesso a máquinas e equipamentos). Seu uso é percebido, porém, tornase insuficiente para operar esta partilha. Daí o segundo marcador presente, a 
seguir discriminado.

b. Pode um marcador de adequação sociotécnica corresponder à capacidade de chegar ao questionamento dos limites da apropriação da base técnica? Sim. A literatura AST tem afirmado que a gestão coletiva de máquinas, equipamentos, meios organizacionais disponíveis não é apenas um ato de consumo (de tecnologia). Configura-se como oportunidade para os grupos relevantes iniciarem um estágio de adequação de sua experiência prévia a outro estágio futuro, como modificação do conhecimento por parte do/ as trabalhadores/as quanto aos aspectos produtivos (fases de produção, cadeia produtiva, funcionamento do maquinário, problemas de gestão internos aos grupos familiares e externos nos mercados). Esse processo de apropriação, contudo, apresenta limites. (Um deles é a barreira imposta pela subordinação ao modelo de inovação tecnológica convencional). Não são as formas privadas que diretamente se contrapõem ao grupo relevante, mas é a subordinação a projetos governamentais que traduz o privado sob outras formas de interesses inseridos na tecnologia padrão la cisterna convencional é de plástico PVC), no caso da ASA. Metodologicamente tal passo demanda um terceiro marcador estratégico, a seguir discutido.

c. Como pode a adequação sociotécnica se tornar um processo de erros e acertos para aumentar a vida útil das máquinas, equipamentos e dispositivos híbridos sociais e técnicos? 0 repotenciamento é marcado, em experiências de apropriação tecnológica entre grupos populares, pelo domínio de um saber-fazer da manutenção. "Quebrou, consertou” é a regra geral quando não se dispõe de capital de giro para fazer recondicionamento e revitalização do maquinário, instrumentos e peças. Os ajustes e a adoção de soluções imprevistas são maneiras de proceder à hibridização das tecnologias 'antigas' com componentes novos, desde ferramentas até máquinas simples, dispositivos sociotécnicos. Estes são parte fundamental de uma curva de aprendizagem que aparece em processo de desenvolvimento nas experiências do Projeto Dom Helder Câmara e da ASA. Contudo, os elementos disponíveis na literatura não permitem afirmar que esta terceira forma de marcador esteve presente na experiência histórica do PROVE-DF.

d. Pode a adequação sociotécnica ocorrer também por meio de ajustes do processo de trabalho? Sim. As experiências da ASA parecem indicar um grau avançado de adequação dos integrantes às exigências de organização do processo de trabalho dos grupos familiares em transição para coletivos de famílias. Para as comunidades e entidades civis organizadas, esta transição se expressa na produção e conservação de sementes; na gestão coletiva da propriedade e de seus recursos naturais. Na experiência da ASA, o acesso aos meios de 
produção (preexistentes ou convencionais) parece caminhar para um claro questionamento da divisão técnica do trabalho convencional entre quem é técnico e quem é produtor/a. Contrasta, porém, que na experiência do PDHC só tem papel de destaque o técnico ou extensionista, como mediador entre o produtor e a melhoria da qualidade de vida e elevação da produtividade. Emambos os casos (mais na ASA do que no PDHC), esta mediação (conhecimento técnico e experiência popular) é um dos elementos das redes socialmente construídas. As duas experiências apontam a adoção de graus variáveis de autogestão que envolvem não somente resultados finais, mas sobretudo ajustes no processo técnico do trabalho. Este marcador abre possibilidades relacionadas com o acesso a informações e dados externos, inclusive informações técnicas e científicas (a seguir abordado).

e. Quando a adequação sociotécnica pode se configurar como um marcador de busca das alternativas tecnológicas? Em geral, as dimensões da AST anteriores não são suficientes para dar conta das demandas por melhorias sociotécnicas entre empreendimentos autogestionários no complexo agroalimentar. Nesse caso torna-se necessária a busca e seleção de tecnologias existentes. Esta via pode ser convergente ou divergente com as práticas AST. Divergente, como demonstra o caso concreto da experiência da ASA na situação negativa de alternativa tecnológica que conflitava com os dispositivos aceitos socialmente (cisterna de placal diante da produção de cisterna PVC (produto industrial externo). A produção industrial da cisterna inviabilizou os processos socioconstrutivistas e de interacionismo sociotécnico da rede ASA. Tal conflito poderá levar, certamente, a um tensionamento futuro no sentido de a organização popular - quando proceder à busca de alternativas tecnológicas - tomar este episódio como parte da curva de aprendizagem sociotécnica para soluções em escala. Esta questão pode ser mais bem abordada sob o ângulo da incorporação de conhecimento técnicocientífico novo - um marcador chave de maior simetria do saber-fazerdiante do conhecimento técnico.

f. Quando a adequação sociotécnica permite a incorporação de conhecimento científico-tecnológico existente? Quando é percebida a necessidade de aumentar a escala de aplicação (passar da pequena para a grande escala exige conhecimento científico, normas e técnicas de padronização, normatização, etc). Em geral este momento é vivido como um aconselhamento na universidade sobre soluções para problemas específicos (captação de água da chuva mediante sistema de filtragem pós-telhado; aumento da produtividade com produção de SAF - sistema agroflorestal apropriado para o semiárido, soluções agroecológicas que demandam cooperação com o conhecimento 
formal científicol.Esta dimensão está relacionada com o fato de qualquer desenvolvimento de novos processos produtivos ou meios de produção poder ser tanto dirigido para aperfeiçoar demandas específicas de AST, quanto involuntariamente se dirigir para adoção de tecnologia convencional lcom aumento de incertezas). Uma resposta a esta questão se colocou por pressões diante de situações concretas vividas pelos agentes tanto da ASA quanto do PDHC. Daí a importância do sétimo e último marcador.

g. 0 processo de incorporação de conhecimento científico-tecnológico novo depende de uma negociação? Certamente. Este marcador final corresponde a um estágio avançado no qual a mobilização de conhecimento científico novo só pode se dar se forem construídas mediações entre pesquisadores científicos e grupo relevante na base social. Grupos técnicos e profissionais, (redes técnicas) em geral envolvidos em assessorias, integram a posição de quem detém o conhecimento situado numa suposta "fronteira" avançada. Tal fronteira, contudo, existe na maioria dos casos em estágio de laboratório na universidade (afastado da sociedade). As experiências aqui apresentadas indicam que há um processo de negociação entre os que estão dentro (do campo científico e tecnológicol e os que estão fora (interesses práticos de aplicação). No caso histórico das fabriquetas rurais, este nível da adequação não teve tempo para adquirir maturidade. Nas experiências atuais do PDHC e da ASA, não foi identificado interesse por conhecimentos novos. Mas isso provavelmente ocorrerá luma tendência positiva é a presença nos dois programas de pesquisas agroecológicas locais sobre manejo regenerativo de plantas-solos-clima para melhoria de forragens de pequenos rebanhos, enquanto conhecimento novol.

\section{Conclusões}

Como conclusão geral, é bom recordar que todos os sete marcadores de AST aqui discutidos recolocam totalmente em questionamento as ideias, certezas ou noções vinculadas à educação rural, associada a assistência técnica e extensão rural, que geralmente levam pacotes prontos de soluções para os sujeitos do campo. Esta crítica lantiga, pois recebeu um tratamento exemplar de Paulo Freire em Extensão ou Comunicação nos anos 1960) parte, de fato, de um diagnóstico filosófico, pedagógico e político-educacional da relação do Estado e do mercado com a educação e as experiências do saber-fazer do campesinato latino-americano. (Freire, 1983) 0 diagnóstico freireano continua atual. Extensão e invasão cultural têm sido sinônimos. Este desafio de uma política de educação 
científica no campo pode ser equacionado quando as mudanças em busca de alternativas para os modos de produção camponeses alinham-se às formas de resistência das comunidades camponesas e às soluções sociotécnicas, como expressões de uma mesma temporalidade. Sabemos, entretanto, que cabe uma exceção para a política educacional, que tem mudado para incorporar o conceito de "educação do campo". Esta política tem recebido um importante reforço no Brasil com a implantação, desde meados da década passada, da política nacional de educação do campo no contexto dos movimentos pela reforma agrária. Os projetos educacionais para grupos socialmente discriminados no campo lcomo o Programa de

apoio à Formação Superior em Licenciatura do Campo e a Política Nacional de Educação para a Reforma Agrárial destinam recursos para as regiões com baixa renda a fim de promover o desenvolvimento local e reduzir as desigualdades sociais. Ainda não existe um desenho organizacional para garantir a convergência acima com a mesma temporalidade, com forte viés integrador para uma política articulada entre pesquisa científica e educação do campo para todas as esferas do executivo no território (municipal estadual e federal). Isto foi tentado inicialmente no âmbito dos Territórios da Cidadania (Brasil-Mda, 2011) sem clara efetividade até 2012. Estas soluções são insuficientes, via de regra, por terem origem na disseminação da invisibilidade de um modelo cognitivo para ampliar o entendimento dos marcadores das experiências formativas das comunidades, como parte orgânica das suas condições de vida e trabalho, produção e cidadania entre grupos da agricultura familiar e campesinato.Uma das conclusões deste artigo refere-se, portanto, à questão da cidadania que poderíamos qualificar sob o enfoque sociotécnico ou de direito à tecnologia. Trata-se do modelo convencional de cidadania como um conjunto de franquias entre as quais está a educação formal e os anos de frequência regular à escola que resultarão no diploma e certificados. Se encararmos este processo como elo de uma cadeia de franquias para acesso à cidadania plena, então mais da metade da sociedade brasileira não poderá acessar os direitos formais de cidadania, entre eles o campesinato e os contingentes da agricultura familiar. Tidos comoincapazes que são de lidar com a política de aprendizagem e capacitação social e técnica para acessar melhores condições de crédito e assistência técnica, estes contingentes são assim obrigados a entrar numa corrida permanentemente desfavorável. Esta visão - tal a como a fábula da tartaruga e da lebre - deve ser desconstruída a começar pelo sistema formal de escolarização. As contribuições da pesquisa que deram origem a este artigo visam a realizar esta desconstrução, e propor uma reconstrução. Os dados apresentados não tiveram o objetivo de analisar, por exemplo, se a atual política de licenciatura da educação do campo (Ledoc) desempenha um papel 
importante neste sentido. Certamente contribui. Contudo, só podemos afirmar com base nos dados aqui apresentados que o modelo de escolarização Ledoc, em processo de ser oficialmente incorporado mediante um conjunto de experiências de currículo no Brasil, só poderá prosperar se as experiências associadas às mudanças sociais e às mudanças da base técnica forem incorporadas em sua estrutura de ensino e reprodução de conhecimentos. Do ponto de vista metodológico, é conveniente lembrar a base de experiências formativas; contudo, não deve ser mistificada, tampouco menosprezada. Tal base tem sido valorizada pelos pesquisadores das ciências naturais e físicas nas universidades e institutos de pesquisa no País na medida em que os saberes locais e da sua valorização resultam em informações técnicas de pesquisa que aumentam a expropriação e exploração de saberes sob um neocolonialismo. 0 que se busca, pela proposta aqui formulada dos setes marcadores, ao contrário, é oferecer uma base teóricometodológica baseada nos estudos CTS sobre a via de mão dupla da simetria cognitiva entre saberes - acerca da agrobiodiversidade, medicina fitoterápica, solos e minerais - e a base científica. Por fim, uma última dimensão-chave aqui discutida de experiência formativa, baseada em oportunidades para pequena industrialização rural: este tipo de locus do saber-fazer na produção gera grandes possibilidades de criar manufaturas - aliás, historicamente originadas das comunidades rurais em todo o mundo, em várias épocas históricas antes da indústria capitalista tal como a conhecemos hoje no Brasil, na Europa ou nos Estados Unidos. (Gama, 1986, Senett, 2009) Diferentes tipos de bloqueios complicam o acesso ao fomento e transferências públicas sistemáticas nesta área da pequena agroindustrialização e do estímulo às cadeias de manufatura. A maior riqueza deste campesinato - sua heterogeneidade sociocultural vinculada aos biomas e regiões específicas, aliada à sua diversidade étnica - se expressa pelo domínio de diferentes artefatos, técnicas e sistemas de auto-organização entrelaçados. Os anos de escolarização formal são reduzidos e é precário acesso à educação formal pelo campesinato e indígenas? Sem dúvida, mas isto não thes traz maiores prejuízos, exceto quando tomamos tal afirmação acriticamente, sem levar em conta que são parte de um conjunto de mecanismos de elegibilidade e seletividade aos quais se junta a escolarização como rito de passagem para fazer com que somente os corpos escolarizados possam se fazer representar perante o Estado. 


\section{Referências}

ABRAMOVAY, Ricardo. A rede, os nós, as teias: tecnologias alternativas na agricultura. Revista de Administração Pública. Rio de Janeiro, v. 6, n. 34, pp. 159-77, nov./dez. 2000.

ALBUQUERQUE, Maria do Carmo. Novos paradigmas no semiárido brasileiro: a experiência da ASA na construção de novas modalidades de políticas. In: MORAIS, Leandro; BORGES, Adriano. Novos paradigmas de produção e consumo. Experiências inovadoras. São Paulo: Instituto Pólis, pp. 144-177. 2010.

ALMEIDA, Jalcione. Propostas tecnológicas "alternativas" na agricultura. Cadernos de Difusão Tecnológica. Brasília, v. 6, n. 2/3, maio/dez. pp. 183-216. 1989. ALMEIDA, Jalcione; NAVARRO, Zander. Reconstruindo a agricultura: idéias e ideais na perspectiva de um desenvolvimento rural sustentável. Porto Alegre: UFRGS, v. 1, 1997. 322 p.

ALVES, Eliseu. Agricultura familiar: prioridade na Embrapa. In: ALVES, Eliseu. Migração rural-urbana, agricultura familiar e novas tecnologias - Coletânea de artigos revistos. 1. ed. Brasília: Embrapa Informação Tecnológica, 2006. AQUINO, Joacir Rufino; SCHNEIDER, Sergio. Dimensão e localização do público potencial do PRONAF "B" no Brasil: uma análise a partir do Censo Agropecuário 2006. In: CONGRESSO BRASILEIRO DE ECONOMIA E SOCIOLOGIA RURAL, 49. 2011, Belo Horizonte. Anais... Belo Horizonte: SOBER, 2011.

ASA Articulação do Semi-Árido. Tecendo vida, fomentando sonhos e construindo novas relações sociais no semiárido brasileiro. In: ENCONTRO NACIONAL DE ARTICULAÇÃO DO SEMI-ÁRIDO BRASILEIRO, 6, 2006, Recife, Anais... Recife: AsaCom. 2006. (Carta Política).

Mãos que constroem. A experiência das mulheres no semiárido brasileiro. Recife: AsaCOm, 2009.

Cisternas.Disponível em: <www.Asabrasil.org.br/Portal/informacoes. asp?COD_MENU+5622\&WORDKEY+Cisterna]>.> Acesso em: 17 abr. $2014 a$.

P1MC. Disponível em: <asabrasil.org.br//Portal/informações.asp?COD_ MENU=1150]>. Acesso em: 17 abr. 2014c.

Declaração do Semiárido Brasileiro. Disponível em: <www.asabrasil.org. br//Portal/informacoes.asp?COD_MENU=5635>. Acesso em: 17 abr. $2014 \mathrm{~d}$.

Cisternas de Plástico/PVC - Somos Contra! Disponível em: <www. asabrasil.org.br//Portal/informacoes.asp?COD_MENU=5635>. Acesso em: 17 abr. 2014d

BAUMGARTEN, Maira. Políticas de CT\&l: heranças do passado e tendências atuais. Jornal da Ciência. Rio de Janeiro, 1 dez. 2008. Notícias. Disponível em: <http://www.jornaldaciencia.org.br/Detalhe.jsp?id=60239>. Acesso em: 24 maio 
2014.BENAKOUCHE, Tamara. Tecnologia é sociedade: contra a noção de impacto tecnológico. In:

NEDER, Ricardo Toledo (Org). CTS ciência, tecnologia, sociedade e a produção de conhecimento na universidade. Brasília. Observatório do Movimento pela Tecnologia Social na América Latina. UnB/CAPES-Escola de Altos Estudos. Cadernos Primeira Versão. Serie I. Construção Social da Tecnologia. Numero 4, 2013 (115-140). BENINI, Édi; FARIA, Mauricio Sardá; NOVAES, Henrique; DAGNINO, Renato. Gestão pública e sociedade. Fundamentos e políticas públicas de Economia Solidária. 1a. ed. São Paulo: Outras Expressões, v. I, 2012. 479 p.

BONNAL, Philipe; COZELLA, Ademir; MALUF, Roberto. Multifuncionalidade da agricultura e desenvolvimento territorial: avanços e desafios para a conjunção de enfoques. Estudos Sociedade e Agricultura. Rio de Janeiro, v. 16, n. 2, abr. pp. 185227, 2008.

BRANDÃO, Flavio Cruvinel. Programa de apoio às tecnologias apropriadas - PTA Avaliação de um programa de Desenvolvimento tecnológico induzido pelo CNPq. 2001. 191 p. Dissertação (Mestrado em Políticas e Gestão de Ciência e Tecnologia) Centro de Desenvolvimento Sustentável, Universidade de Brasília, Brasília.

Uma história brasileira das tecnologias apropriadas. 1. Ed. Brasília: Paralelo 15/ABIPTI, 2006. 244 p.

BRASIL. Lei n. 6.746, 10 dez. 1979. Altera o disposto nos arts. 49 e 50 da Lei n. ${ }^{\circ}$ 4.504, de 30 de novembro de 1964 (Estatuto da Terra), e dá outras providências.

BRASIL. Lei n. 8.629, 25 fev. 1993. Dispõe sobre a regulamentação dos dispositivos constitucionais relativos à reforma agrária, previstos no Capítulo III, Título VII, da Constituição Federal. Disponível em: <http://www.planalto.gov.br/ccivil_03/leis/ L8629.htm>. Acesso em: 05 maio 2014.

BRASIL-IBGE. Censo Agropecuário - Agricultura Familiar - Primeiros Resultados. Rio de Janeiro, 2009a. 265 p.

Censo Agropecuário - Brasil, Grandes Regiões e Unidades da Federação. Rio de Janeiro, 2009b. 775 p.

BRASIL-MCT. Seleção Pública de Propostas para Apoio a Projetos de Extensão Tecnológica Inovadora para Agricultura Familiar. Edital, Brasília, n. 36, 2007. Disponível em: <http://www.cnpq.br/editais/ct/2007/docs/036.pdf>. Acesso em: 12 maio 2012.

BRASIL-MDA Estatísticas do meio rural 2010-2011. 4.ed. / Departamento Intersindical de Estatística e Estudos Socioeconômicos; Núcleo de Estudos Agrários e Desenvolvimento Rural; Ministério do Desenvolvimento Agrário. -- São Paulo: Departamento Intersindical de Estatística e Estudos Socioeconômicos e Núcleo de Estudos Agrários, 2011. 292 p. Disponível em: <http://www.nead.gov. $\mathrm{br} / \mathrm{portal} / \mathrm{nead} /$ institucional/busca?cx=006027766869131785344\%3Axpaxf63rt6 
$w \&$ cof $=F O R I D \% 3 A 10 \& i e=U T F-8 \& q=$ estatistica+do+meio+rural\&sa>. Acesso em: 25 abr. 2014. BRASIL-MDS. Plano Brasil sem Miséria. 2011. 16 p. Disponível em: <http://www.brasilsemmiseria.gov.br/wp-content/themes/bsm2nd/caderno_ brasil_sem_miseria.pdf $>$. Acesso em: 12 fev. 2014.

BRASIL-MEC. Resolução n. 6, 17 de março de 2009. Estabelece as orientações e diretrizes para a operacionalização da assistência financeira suplementar aos projetos educacionais que promovam o acesso e a permanência na universidade de estudantes de baixa renda e grupos socialmente discriminados. Diário Oficial [da] República Federativa do Brasil, Brasília, v. 146, n. 52, p. 17, 18 mar. 2009. Seção 1.

BRASIL-MI. Política Nacional de Desenvolvimento Regional. 2007. Disponível em:<http://www.mi.gov.br/download/download.asp?endereco=/pdf/ desenvolvimentoregional/pndr.pdf\&nome_arquivo=pndr.pdf $>$. Acesso em: 29 maio 2014.

BUAINAIN, Antonio Marcio. DEDECCA, Claudio. Mudanças e Reiteração da Heterogeneidade do Mercado de Trabalho Agrícola In: GASQUES J. G.; VIEIRA FILHO, J; E. R.; NAVARRO, Zander. A agricultura brasileira: desempenho, desafios e perspectivas. Brasília: IPEA, 2010. pp. 123-153.

CAATINGA. Semeando Vida no Semiárido.Ouricuri: Centro de Assessoria e Apoio aos trabalhadores e Instituições Não-Governamentais Alternativa. Disponível em: <http://wwwcaatinga.org.br/>. Acesso em: 17 abr. 2014.

CARTER, Michel. Combatendo a desigualdade social: o MST e a reforma agrária no Brasil. Tradução de Cristina Yamagami.São Paulo: Unesp. 2010. 564 p. Título original: Challenging social inequality: the Landless Rural Workers Movement (MST) and agrarian reform in Brazil.

CARVALHO, Henrique. Tecnologia socialmente apropriada: muito além da questão semântica. Londrina: IAPAR, 1982. 36p.

DAGNINO Renato; VELHO, Léa. A relação universidade-indústria-governo em países periféricos - o caso da Universidade de Campinas. In: DAGNINO, R.; THOMAS, H. (Orgs). A pesquisa universitária na América Latina e a vinculação universidadeempresa. Chapecó: Argos. 2011. pp. 111-154

DAGNINO, Renato. Ciência e Tecnologia no Brasil: o processo decisório e a comunidade de pesquisa. Campinas: UNICAMP. 2007. 215 p. DAGNINO, Renato. Neutralidade da viência e determinismo tecnológico. Campinas: Unicamp. 2008.

(Org.) Tecnologia social: ferramenta para construir outra sociedade. 2. ed. rev. e ampl. Campinas: Komedi. 2010a. 306 p.

(Org.) Estudos sociais da ciência e tecnologia \& política de ciência e tecnologia - alternativas para uma nova América Latina. Campina Grande: Eduepb/Unicamp. 2010b. 327 p. 
DAGNINO, Renato; BRANDÃO, Flávio; NOVAES, Henrique. Sobre o marco analíticoconceitual da tecnologia social. In: DAGNINO Renato. (Org.) Tecnologia social: ferramenta para construir outra sociedade. 2. ed. rev. e ampl. Campinas: Komedi. 2010. pp. 71-111.

DAGNINO, Renato; THOMAS, Hernan (Org.) A pesquisa universitária na América Latina e a vinculação universidade-empresa. Chapecó: Argos. 2011. 311 p.

DAGNINO, Renato; THOMAS, Hernan; DAVYT, Amilcar. El pensamiento en Ciencia, tecnología y sociedad en América Latina: una interpretación política de su trayectoria. Redes, Buenos Aires, v.3, n.7. 1996. pp. 13-51.

DELGADO, Guilherme. A questão agrária e o agronegócio no Brasil. In CARTER, M. Combatendo a desigualdade social: o MST e a reforma agrária no Brasil. São Paulo: Unesp, 2010. pp. 81-112.

FEENBERG, Andrew. Between reason and experience. Essays in technology and modernity. 1a ed. Cambridge: The MIT Press. 2010. 247 p.

FERNANDES, Bernardo Marçal. Brasil: 500 anos de luta pela terra. Revista Cultura Vozes, São Paulo, n. 2, mar./abr. 1999. pp. 11-31.

Formação e territorialização do MST no Brasil. In: CARTER, M. (Org.) Combatendo a desigualdade social - O MST e a reforma agrária no Brasil. Tradução de Cristina Yamagami. 1. ed. São Paulo: Unesp. 2010. pp. 161-197. Título original: Challenging social inequality: the Landless Rural Workers Movement (MST) and agrarian reform in Brazil.

FREITAS, Claiton Ataide; BACHA, Carlos José Caetano; FOSSATTI, Daniele Maria. Avaliação do desenvolvimento do setor agropecuário no Brasil: período de 1970 a 2000. Economia e Sociedade, Campinas, v. 16, n. 1, pp. 111-124, abr. 2007.

FURTADO, Celso. Subdesenvolvimento e estagnação na América Latina. 1. ed. Rio de Janeiro: Civilização Brasileira, 1966. 127 p.

Teoria e política do desenvolvimento econômico. Rio de Janeiro: Nacional, 1967. $344 \mathrm{p}$.

Um projeto para o Brasil. Rio de Janeiro: Saga, 1968. 136 p. Análise do modelo brasileiro. Rio de Janeiro: Civilização Brasileira. 1972.122 p. 0 Mito do desenvolvimento econômico. Rio de Janeiro: Paz e Terra. 1974, 89 p. FREIRE, Paulo. Extensão ou comunicação? Rio de Janeiro. Paz e Terra, 1983. G AMA, Ruy. A tecnologia e o trabalho na história. São Paulo: Nobel/Edusp, 1986. GORENDER, Jacob. O escravismo colonial. São Paulo: Ática, 1978. 632 p.

GRAZIANO-SILVA, José. O novo rural brasileiro. Campinas: UNICAMP/Instituto de Economia, 1999. 28 p. (Coleção Pesquisas, 1)

GUIMARAES, Alfredo Passos. Quatro séculos de latifúndio. 4. ed. Rio de Janeiro: Paz e Terra, 1977. $196 \mathrm{p}$.

HAYAMI, Y.; RUTTAN, V. Agricultural development: an international perspective. 1. ed. 
Baltimore: Johns Hopkins University Press, 1985. 506 p.

HERRERA, Amilcar. La generación de tecnologias em las zonas rurales. In: DAGNINO R. P. (Org.) Tecnologia social: ferramenta para construir outra sociedade. 2. ed. rev. e ampl. Campinas: Komedi. 2010. pp. 23-52.

IANNI, Otaviani. A sociedade global. Rio de Janeiro: Civilização Brasileira, 1992. 194 p. INCRA. Portaria Instrução Especial n. 51, 26 ago. 1997. Estabelece o Módulo Fiscal para os Municípios constantes da tabela anexo. Diário Oficial [da] República Federativa do Brasil, Brasília, v. 134, n. 176, p. 19243-6, 12 set. 1997. Seção I.KAGEYAMA, Angela. GRAZIANO-SILVA, José. A dinâmica da agricultura brasileira: do complexo rural aos complexos agroindustriais. Campinas: Unicamp, 1987. $54 \mathrm{p}$.

LASSANCE, JÚNIOR. et. al. Tecnologia social - uma estratégia para o desenvolvimento. Rio de Janeiro: Fundação Banco do Brasil, 2004. 216 p.

LITTLE, Paul. Territórios sociais e povos tradicionais no Brasil: por uma antropologia da territorialidade. Série Antropologia, Brasília: Departamento de Antropologia/UnB, n. 322, 2002. $32 \mathrm{p}$.

LOPES, Francisco. Do combate à seca à convivência com o semiárido. A história do Programa UmMilhão de Cisternas Rurais da ASA. 2007. Disponível em: <www. diaconia.org.br/novosite/biblioteca/>. Acesso em: 29 maio 2014.

MARTINE, George. A trajetória da modernização agrícola: a quem beneficia? Lua Nova, São Paulo, n, 23, mar. p. 7-37. 1991. Disponível em: <http://www.scielo.br/scielo. php?script=sci_arttext\&pid=S0102-64451991000100003\&lng=en\&nrm=iso> Acesso em: 11 maio 2014.

MEC-SECAD. Edital e Convocação Nº 09, 29 abr. 2009. Convoca as Instituições Públicas de Educação Superior - IES públicas - para apresentarem projetos de Cursos de Licenciatura em Educação do Campo para a formação de professores da educação básica nas escolas situadas nas áreas rurais. Acesso em: <mec.gov.br/dmdocuments/ edital_procampo_20092.pdf>. Acesso em: 12 fev.2014.

MEDEIROS, Leonilde. Movimentos sociais no campo, lutas por direitos e reforma agrária na segunda metade do século XX. In: CARTER, M. Combatendo a desigualdade social: o MST e a reforma agrária no Brasil. São Paulo: Unesp, 2010. pp. 113-136. NEDER, Henrique. Estrutura do mercado de trabalho agrícola no Brasil: uma análise descritiva da evolução de suas categorias entre 1995 e 2006. In: BUAINAIN, A. M.; DEDECCA, C. S. (Org.). Emprego e trabalho na agricultura brasileira. Brasília: IICA, Série Desenvolvimento Rural Sustentável, v. 9, 2009.

PESSOA, Felipe de Morais. GOMES, Marília Fernandes Marciel. SALVATO, Márcio Antônio.

CORONEL, Daniel Arruda. FREITAS, Claiton Ataíde de Análise das disparidades regionais do setor agropecuário brasileiro, 1995 a 2005 In: CONGRESSO BRASILEIRO DE ECONOMIA E SOCIOLOGIA RURAL, 47., 2009, Porto Alegre. Anais... Porto Alegre: 
SOBER, 2009. 1 CD-ROM

PHDC - Relatório Físico-Financeiro Ações, Resultados, e Impactos. Recife: FIDA/ MDA, 2009. 87 p. Disponível em: <HTTP://www.projetodomhelder.gov.br:8080/notitia/ files/284.pdf>. Acesso em: 12 fev. 2014.

PHDC - Sistemas de Produção Sustentáveis, Assessoria Técnica e Organização da Produção Agropecuária na Perspectiva Territorial: a experiência do Projeto Dom Helder/SDT/MDA/ FIDA. 40 p. (apresentação de slides). Disponível em: <HTTP://www. projetodomhelder.gov.br:8080/notitia/files/74.pdf.> Acesso em: 12 fev. 2014.

PRADO JÚNIOR, Caio. A Questão agrária no Brasil. 2.ed. São Paulo: Brasiliense,1979.188 p. PROCAMPO. 2012. Disponível em: <http://portal.mec.gov.br/index.php?ltemid=673 \&id=12395\&option=com_content\&view=article $>$. Acesso em: 12 fev. 2014.

RIBEIRO, Dario. Os índios e a civilização. Rio de Janeiro: Civilização Brasileira, 1970.

o Povo brasileiro - A Formação e o Sentido do Brasil. 2. ed. São Paulo:

Companhia das Letras, 1995. $477 \mathrm{p}$.

RODRIGUES, Ideli; BARBIERI, José Carlos. A emergência da tecnologia social: revisitando o movimento da tecnologia apropriada como estratégia de desenvolvimento sustentável. Revista de Administração Pública, v.42, n. 6, pp. 1069-94, nov-dez. 2008.

ROMEIRO, Ademar. R. Meio ambiente e dinâmica de inovações na agricultura. 1. ed. São Paulo: Annablume, 1998. 277 p.

ROSENBERG, Natan. Sources of Innovation in Developing Economies: reflections on the Asian experience. Trabalho apresentado no Herrera Lecture, Maastricht: Institute for New Technology, 26 set. 2002. 27 p.

SANTOS, Boaventura de Sousa. (Org.). Semear outras soluções. Os caminhos da biodiversidade e dos conhecimentos rivais. Rio de Janeiro: Civilização Brasileira, 2009. $501 \mathrm{p}$.

SANTOS, Wilson Luiz Pereira dos; AULER, Décio. CTS e Educação científica: desafios, tendências e resultados de pesquisa. Brasília: UnB, 2011. 460 p.

SAWYER, Donald; NOGUEIRA, Monica; MAGALHÃES, Rogério. Entraves regulatórios de atividades extrativistas na Amazônia e Cerrado (Um tema CTS). In: NEDER, Ricardo Toledo (Org.). CTS ciência, tecnologia, sociedade e a produção de conhecimento na universidade. Brasília. Observatório do Movimento pela Tecnologia Social na América Latina. UnB/CAPES-Escola de Altos Estudos. Cadernos Primeira Versão. Serie I. Construção Social da Tecnologia. n. 4, 2013 (pp. 195-226).

SCHNEIDER, Sergio. Histórico, caracterização e dinâmica recente do Pronaf Programa Nacional de Fortalecimento da Agricultura Familiar. In: SCHNEIDER, S.; SILVA, M. K.; MARQUES, P. E. M. Políticas públicas e participação social no Brasil rural. Porto Alegre: UFRGS, 2004, pp. 21-50.

SENNET, Richard. 0 artífice. Rio de Janeiro/São Paulo. Editora Record, 2009

SILVA, Rogerio Bezerra da. A relação universidade-sociedade na periferia do 
capitalismo. In NEDER, Ricardo Toledo (Org.). CTS ciência, tecnologia, sociedade e a produção de conhecimento na universidade. Brasília. Observatório do Movimento pela Tecnologia Social na América Latina. UnB/CAPES-Escola de Altos Estudos. Cadernos Primeira Versão. Serie I. Construção Social da Tecnologia. n. 4, 2013 (pp. 275-303).

THOMAS, Hernan. Tecnologias para inclusão social e políticas públicas na América Latina. 2009. In: FÓRUM NACIONAL DA RTS E CONFERÊNCIA INTERNACIONAL DE TECNOLOGIA SOCIAL, 2., 2009, Brasília. Anais... Brasília: RTS, pp. 25-82, 2009. Tecnologías sociales y ciudadanía socio-técnica: notas para la construcción de la matriz material de un futuro viable. UnB. Ciência \& Tecnologia Social, Brasília, v. 1, n. 1. 2011. Disponível em: <http://seer.bce.unb.br/index.php/cts>. Acesso em: 14 jul. 2012.

VEIGA, José Eli da. Desenvolvimento Agrícola - Uma Visão Histórica. São Paulo: Edusp/ Hucitec, 1991. 219 p. (Estudos Rurais, 11). WANDERLEY, Nazaré. A emergência de uma nova ruralidade nas sociedades modernas avançadas: o "rural" como espaço singular e ator coletivo. Recife: Universidade Federal de Pernambuco, mar. 2000. Mimeografado.

Recebido em julho de 2014 Aprovado em dezembro de 2014

Ricardo T. Nederé doutor em ciências pela Faculdade de Filosofia Letras e Ciências Humanas da (FFLCH) da Universidade de São Paulo (USP). Pós-doutoramento em Sociologia Política do Neocorporativismo (IFCH e Economia UNICAMP), Desenvolvimento Territorial e Regional (UNESP), Filosofia da Tecnologia e Teoria Crítica da Tecnologia - Escola de Frankfurt (USP. FFLCH). Atua na graduação e pesquisa-ação na Faculdade Universidade de Brasília - Planaltina (Gestão do Agro, Ambiental, Ciências Naturais, Educação do Campo e Desenvolvimento Agrário). E-mail: rtneder2010Quol.com.br 